\title{
O mix de marketing em uma feira livre
}

\author{
The marketing mix at a free fair \\ La mezcla de marketing en una feria gratuita
}

Recebido: 28/03/2021 | Revisado: 02/04/2021 | Aceito: 08/04/2021 | Publicado: 19/04/2021

\author{
Abimael Dias Matos \\ ORCID: https://orcid.org/0000-0003-2658-1109 \\ Universidade Estadual do Tocantins, Brasil \\ E-mail: abimaeldmatos@gmail.com \\ Marcos José de Almeida Matias \\ ORCID: https://orcid.org/0000-0002-0643-9941 \\ Universidade Estadual do Tocantins, Brasil \\ E-mail: marcos.ja@unitins.br \\ Mônica de Souza Lima \\ ORCID: https://orcid.org/0000-0003-4457-2011 \\ Universidade Estadual do Tocantins, Brasil \\ E-mail: monica.contadora@yahoo.com.br \\ Denise Barros de Azevedo \\ ORCID: https://orcid.org/0000-0003-0253-8616 \\ Universidade Federal do Mato Grosso do Sul, Brasil \\ E-mail: deniseazevedo1972@gmail.com
}

\begin{abstract}
Resumo
Para o sucesso de uma organização faz-se necessário a utilização de ferramentas capazes de identificar as necessidades e desejos do seu público-alvo. Dessa forma, o objetivo desta pesquisa foi analisar a influência do Mix de Marketing na tomada de decisão do consumidor em uma feira livre. Para tal, foi realizado uma pesquisa de campo na Feira Bela Vista, instalada todas as sextas-feiras na cidade de Dianópolis/TO. A metodologia da pesquisa é de natureza aplicada, com uma abordagem quantitativa, sendo seus objetivos descritivos e pesquisa de campo. $\mathrm{O}$ instrumento utilizado para a coleta de dados foi o questionário estruturado, sendo este aplicado através da plataforma Google forms, a amostra foi composta por 218 clientes respondentes. Este estudo evidenciou-se as influências do mix de marketing na tomada de decisão do consumidor e percebe-se que o consumidor pode ser influenciado por fatores internos e externos.
\end{abstract}

Palavras-chave: Mix de marketing; Comportamento do consumidor; Feira livre.

\begin{abstract}
For the success of an organization it is necessary to use tools capable of identifying the needs and desires of its target audience. Thus, the objective of this research was to analyze the influence of the Marketing Mix in consumer decision making at an open market. To this end, a field research was carried out at Feira Bela Vista, installed every Friday in the city of Dianópolis / TO. The research methodology is of an applied nature, with a quantitative approach, with its descriptive objectives and field research. The instrument used for data collection was the structured questionnaire, which was applied through the Google forms platform, the sample was composed of 218 respondents. This study highlighted the influences of the marketing mix on consumer decision making and it is clear that the consumer can be influenced by internal and external factors.
\end{abstract}

Keywords: Marketing mix; Consumer behavior; Open market.

\section{Resumen}

Para el éxito de una organización es necesario utilizar herramientas capaces de identificar las necesidades y deseos de su público objetivo. Así, el objetivo de esta investigación fue analizar la influencia del Marketing Mix en la toma de decisiones del consumidor en un mercado abierto. Para ello, se realizó una investigación de campo en Feira Bela Vista, instalada todos los viernes en la ciudad de Dianópolis / TO. La metodología de investigación es de carácter aplicado, con enfoque cuantitativo, con sus objetivos descriptivos y de campo de investigación. El instrumento utilizado para la recolección de datos fue el cuestionario estructurado, el cual fue aplicado a través de la plataforma de formularios de Google, la muestra estuvo compuesta por 218 encuestados. Este estudio destacó las influencias del marketing mix en la toma de decisiones del consumidor y está claro que el consumidor puede verse influenciado por factores internos y externos.

Palabras clave: Marketing mix; Comportamiento del consumidor; Mercado abierto. 


\section{Introdução}

O marketing e suas ferramentas têm em seu conceito a exposição, criação e a agregação de valor ao cliente, todavia, para que isso ocorra, é preciso tanto identifica os benefícios e os pequenos diferenciais que são valorizados pelos clientes, quanto avaliar a importância que a criação desse benefício trará para a organização; examinar como os clientes avaliam o desempenho do empreendimento frente aos concorrentes e monitorar se tais benefícios estão sendo suficientes para a atração e fidelização dos clientes (Kotler \& Keller, 2012).

Assim surgem os 4Ps (produto, preço, praça e promoção), ferramenta criada com o propósito de exercer influência sobre os canais comerciais e consumidores finais, criando assim valores para os clientes e benefícios para a organização, representando assim a visão que a empresa vendedora tem das ferramentas de marketing disponíveis (Guimarães, 2012).

Para Churchill Jr. e Peter (2006), os elementos do Mix de Marketing (produto, preço, praça e promoção) trata-se de uma ferramenta utilizada nas estratégias de marketing para gerar valor aos clientes ao e alcançar as metas que foram estabelecidas pela organização: ganha-ganha.

No entendimento de Kotler e Keller (2012), para se entender como agregar valor ao cliente, é preciso identificar os pontos fortes e fracos do empreendimento e, a partir dos seus pontos fortes, analisar o que pode ser visto pelo consumidor como um valor, ou como um ponto que diferencie seu negócio da concorrência.

Nesse contexto, essa pesquisa buscou responder o seguinte problema de pesquisa: Qual a influência do Mix de Marketing na tomada de decisão do consumidor em uma feira livre? Para tal foi traçado o objetivo geral de analisar a influência do Mix de Marketing na tomada de decisão do consumidor em uma feira livre.

Portanto, esse trabalho torna-se justificável pois para os negócios o conhecimento acerca do seu cliente é vital para o progresso, continuidade e saúde financeira do mesmo, como é o caso do ambiente que se encontram os feirantes em Dianópolis/TO.

\section{Referencial Teórico}

\subsection{Conceitos de Marketing}

Segundo Kotler e Keller (2012) o marketing envolve a identificação e a satisfação das necessidades do consumidor final, sendo definido de uma maneira simples, como uma forma de suprir necessidades afim de obter lucro.

Acerca da importância do marketing, Kotler e Keller (2012) afirmam que esta ferramenta está inserida em todos os negócios, seja de uma forma formal ou na informalidade. Destacam ainda que a partir da primeira década do século XXI, onde havia um cenário econômico turbulento, o marketing se destacou no desempenho fundamental para o enfrentamento dos desafios. Tal importância que também é estendida até as organizações sociais.

Alguns fatores analisados por Silva et al., (2003), mostram que a utilização de ferramentas estratégicas hoje é considerada um fator importante no crescimento e desenvolvimento organizacional.

Nesse sentido, Kotler (2000), entende que cada negócio precisa avaliar periodicamente suas forças e fraquezas internas. Analisam-se as competências de marketing, financeiras, de fabricação e organizacionais e classifica cada fator como uma grande força, uma força, uma característica neutra, uma fraqueza ou uma grande fraqueza.

\subsection{Estratégias do Mix de Marketing}

O mix de marketing, segundo Kotler (2005), se trata de um conjunto de ferramentas que a empresa utiliza na busca dos seus objetivos de marketing no mercado alvo. Ressalta o autor que o mix de marketing complementa os instrumento e parâmetros utilizados no processo decisório.

De acordo com Kotler e Keller (2012) a ferramenta de mix de marketing são denominadas por 4Ps do marketing: preço, 
produto, praça e promoção.

Verifica-se, na Figura 1 os 4ps do Mix de Marketing, destacados por Kotler e Keller (2012), a competência dos 4Ps do Mix de Marketing, ou seja, os atributos que envolvem o produto, o preço, a praça e a promoção.

Figura 1 - Os 4Ps do Mix de Marketing.

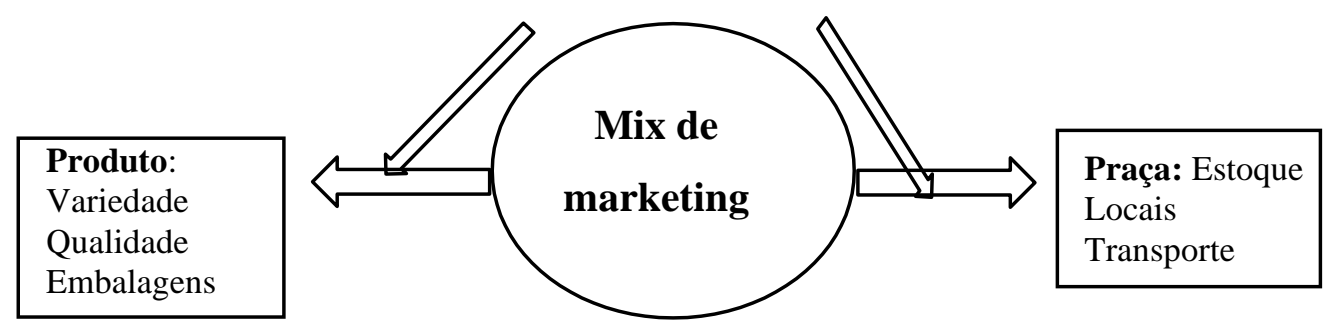
Preço: Meios
de pagamento
Preço de lista
Descontos

\section{Promoção: \\ Propaganda \\ Promoção de \\ venda}

Fonte: Autores, com base em Kotler e Keller (2012).

O Mix de Marketing possui como foco o desenvolvimento de decisões estratégicas em quatro áreas: produto, preço, praça e promoção, mais conhecidos como os quatro p’s de marketing (czinkota \& dickson, 2001).

No entendimento de Kotler (2000) os 4Ps juntos formam o planejamento de marketing que servirá como auxiliar nas tomadas de decisões de uma organização, em relação ao seu mix. Corroborando para o entendimento da figura acima, Guimarães (2012), destaca que os 4Ps do mix de marketing surgem para o desempenho de influência sobre canais comerciais e público alvo, com o objetivo de gerar valores para os cliente e benefícios para a organização, caracterizando uma visão sistêmica para a empresa.

Churchill e Peter (2005) enfatizam que o mix de marketing se trata da junção de ferramentas estratégicas que são utilizadas com o objetivo de agregar valor para os clientes e por conseguinte o alcance dos objetivos da organização.

No entanto, em virtude da complexidade do marketing, Kotler e Keller (2012), afirmam que esses "Ps" ilustrados na Figura 1 já não representam mais todo o campo do marketing moderno, sendo estes completados e atualizados para um conjunto mais representativo com novos "Ps": pessoas, processos, programas e performance, sendo, estes, os 4ps da moderna administração de marketing.

Nessa visão moderna da administração do marketing, de acordo com Kotler e Keller (2012), o marketing está a serviço do consumidor e a serviço da empresa, com o objetivo de gerar resultados ao mesmo tempo que posiciona o consumidor no centro.

Complementa ainda os autores, a respeito dos 4ps modernos, que, em pessoas, a empresa tende a envolver todo o grupo que faz parte do processo de marketing, ou seja, esse processo de fidelização e agregação de valor começa pelos funcionários e chega aos consumidores, não os vendo mais, respectivamente, apenas como trabalhadores e compradores, mas sim como seres humanos e toda sua complexidade.

Já processos, ainda segundo os autores, abrange a tecnologia e os processos que são desenvolvidos pela empresa com o objetivo de entregar valor ao mercado. Os processos precisam estar munidos de inovações que possam estar sendo ofertadas aos 
consumidores. Em programas, os autores ressaltam que nesse objeto está inseridos os "antigos 4ps" dentre outras atividades que a empresa programa direcionada para o consumidor. Por último a Performance, para os autores, se trata da supervisão de desempenho das ações de marketing através dos indicadores de resultados, que necessitam de constante acompanhamento por gestores da área de marketing com (Kotler \& Keller, 2012).

Por sua vez, diante das inúmeras ferramentas de marketing usadas para o planejamento e desenvolvimento de estratégia de satisfação de clientes, Nassaralla (2006), entende que o mix de marketing ainda continua sendo muito utilizado pelas empresas como uma ferramenta para coletar informações a respeito da satisfação dos clientes. Isso é devido a geração de informações valiosas que são capitadas quando se utiliza o 4ps como base de coleta de dados, relacionando assim a satisfação dos clientes com a qualidade do produto oferecido, com a política de preços, a boa comunicação e a localização da empresa.

Para um melhor entendimento a respeito dos elementos do mix de marketing (modelo mais difundido e aceito inclusive pelos principais autores da área), e de como os 4Ps se relacionam com a entrega de valores aos clientes, a seguir será abordado cada "P" de forma particular.

\subsubsection{Produto}

No entendimento de Kotler e Armstrong (2007) o conceito de produto é mais abrangente do que simplesmente os bens tangíveis, ou seja, deve-se, também, incluir ao seu conceito os serviços, organização, eventos, pessoas, lugares etc. Coaduna-se com essa reflexão Las Casas (2006), quando ressalta que o produto se trata de uma junção de atributos tangíveis (cor, embalagem, design) e intangíveis (reputação da marca, prestação de serviços pós-venda) que juntos, quando disponibilizados a um mercado para consumo, uso, aquisição ou apreciação deve ter como objetivo satisfazer uma necessidade ou desejo.

Nesse sentindo, Las Casas (2006), ressalta que o principal objeto de um ambiente de comercialização é o seu produto. Nesses termos e com o mesmo pensamento, Kotler e Armstrong (2007) enfatizam a importância do produto, destacando este objeto como um elemento-chave de uma proposta para o mercado. Ainda, acrescenta os autores, que o planejamento do mix de marketing se inicia com a construção de ofertas que proporcione valor aos clientes-alvos. É através dessas ofertas que a empresa construirá uma base sólida de relacionamentos lucrativos com os clientes.

É importante ressaltar, segundo Las Casas (2006) que serviços se trata de uma transação realizada tanto por um indivíduo quanto por uma empresa, desde que para ambos não esteja associado a transferência de algum bem. Jardim (2005) corrobora assegurando que serviços traz ideia de intangibilidade, pois não possuem estruturas físicas, tampouco podem ser examinados ou avaliados antes de sua contratação ou compra. Para Kotler (2007) é denominado serviço aquele ato, função ou ocupação que uma parte oferece a outra, desde que este seja intangível e que não relação de posse. Porém sua produção pode estar ligada a um produto físico em sua execução.

\subsubsection{Preço}

Com base nos autores Czincota e Dickson (2001), uma das variáveis de suma importância que deve ser analisado e determinado em uma empresa é o preço, pois através da sua determinação se alcança a estratégia de marketing de um determinado produto, há o alcance de metas financeiras, e ocorre também, através desse objeto, o ajuste de realidade do ambiente comercial no qual a empresa ou organização está inserido.

Corroborando, Kotler e Keller (2012), destacam que o único elemento do mix de marketing que gera receita para a empresa é o preço, já os outros "P” são responsáveis por gerarem custos. Ainda para o autor, o preço também é um dos elementos mais flexíveis, já que ele se encontra em constantes alterações. Las Casas (2006) entende que um dos grandes responsáveis por essas alterações e a definição do preço é a concorrência. Completa ainda o autor, que os fornecedores juntamente aos consumidores fazem parte de uma variável muito importantes no desenvolvimento das estratégias de preços das empresas. 
No entendimento de Las Casas (2006) a precificação contribui para a valorização das coisas, representando ainda uma troca entre os esforços feitos pela empresa prestadora, através de sua alocação de recursos e por seus produtos comercializados. Esse elemento também é classificado por Kotler e Armstrong (2007) como a quantia que é cobrada por um determinado produto ou serviço, sendo, este valor cobrado, o resultado da soma de todos os valores e benefícios incluídos na obtenção ou na utilização de um produto ou serviço.

A precificação final para Kotler e Keller (2012) não está associada a algo subjetivo e simples, segundo o autor, é atratividade e o volume de vendas estão diretamente ligados aos níveis de preço.

\subsubsection{Praça}

O "P" de praça, de acordo com Kotler e Armstrong (2007) é incumbido nomeadamente pela forma que o cliente encontra uma empresa, pela forma que o consumidor chega até determinada organização, aos seus produtos e aos seus serviços, ou seja, corresponde a acessibilidade da empresa.

De acordo com Las Casas (2006) a garantia de venda não está unicamente associada a um preço compatível e a um bom produto, necessitam, também, que exista uma forma útil para que os produtos ou serviços cheguem até o consumidor final e atinja o objetivo de ambos, consumidor e vendedor. Isso acontece devido costume de os consumidores estarem ligados à acessibilidade, praticidade e disponibilidade de um produto quando necessário a eles.

\subsubsection{Promoção}

A respeito da promoção, Kotler (2000), afirma tratar-se de ações que incorrem sobre determinado produto ou serviço com o intuito de obter a sua venda ou contratação. Las Casas (2006) ressalta que essa variável é controlável e pode ser definida como o ato de se comunicar com o consumidor.

Segundo Kotler e Armstrong (2007) os instrumentos de comunicação podem ser definidos como a principal ferramenta dentro da variável promoção, que é composta por: promoção de vendas, relação de publicidade, força de venda, propaganda e o marketing direto. Para os autores, o marketing moderno requer bem mais do que um bom produto e preço competitivo para o consumidor, ou seja, também precisa exigir, de modo consistente, uma relação de proximidade entre cliente e empresa, devendo essa aproximação existir tanto com os clientes já existentes como com aqueles em potenciais.

A promoção é composta por elementos como: propaganda, vendas pessoal, relações públicas e a promoção dos produtos. As decisões tomadas através destes elementos agenciam a distribuição dos produtos para o consumidor. Ou seja, a comunicação entre as decisões de promoção é de fundamental importância para que as estratégias de marketing estejam voltadas para a distribuição de produtos para o mercado (Czinkota \& Dickson, 2001).

A respeito da definição de propaganda, Las Casas (2006), ressalta que a propaganda se trata de qualquer forma para propagar informações que apresente ideias, produtos ou serviços, divulgadas, desde que seja paga e sendo vedado o anonimato do propagador de informações.

Já para Churchill e Peter (2000) a propaganda se trata de qualquer meio comunicativo e persuasivo difundida por meios de comunicação de massa por um período, sendo feitos por meios pagos ou doados por outrem. Kotler e Armstrong (2005, p.48) complementam que "promoção envolve as atividades que comunicam os pontos fortes do produto e convencem os clientes-alvo a comprá-lo".

Afim de entender a importância do Mix de Marketing para um ambiente comercial e como o manuseio dessa ferramenta afeta o comportamento dos consumidores, far-se-á necessário a abertura de um subtítulo para um melhor esclarecimento acerca do tema comportamento. 


\subsubsection{Tipos de Tomadas de Decisão dos Consumidores}

Em geral, de acordo com Churchill Jr. e Peter (2005), a importância que o consumidor dá para uma determinada compra é o que definirá a sua decisão final de compra, ou seja, os consumidores não seguem rigorosamente as etapas do processo de decisão de compra. Ainda, de acordo com os autores, para que todas as etapas do processo de decisão sejam cumpridas é necessário que exista alguma das seguintes condições: o consumidor se importar com a compra, o produto ter o preço muito alto, o produto ser complexo ou uma novidade, e existir várias opções de marca.

Ainda sob as perspectivas dos autores, há três tipos de tomadas de decisões dos consumidores, sendo estas: rotineira, limitada e extensiva.

No entendimento de Churchill Jr. e Peter (2005) a tomada de decisões rotineira representa as decisões de compra de baixa importância para os consumidores, portanto os mesmos não se envolvem tanto com a compra. Para o autor, esse processo de decisão ocorre em sua maioria na compra de produtos mais simples, baratos e que o consumidor já conhece.

A decisão rotineira é um tipo de decisão estabelecida pelo fato de haver uma um ou poucas variedades de marcas, poucas diferenciações entre as marcas em termos de características, como o preço, cor, ou até mesmo a velocidade da entrega do produto (Churchill \& Peter, 2005).

Portanto, para Churchill Jr. e Peter (2005) nesse tipo de decisão o consumidor tende a optar por uma marca o qual esteja familiarizado, por afinidade, gosto ou até mesmo indicações de pessoas conhecidas. Esse tipo de decisão, segundo os autores, ocorre de forma comum e corriqueira com os clientes que frequentam um determinado supermercado, onde optam sempre pela mesma marca, sem que ocorra uma pesquisa de custo-benefício de cada uma, pois, nessa tomada de decisão os consumidores optam também pela facilidade e economia de tempo na busca de uma marca, afim de atender esse público, os profissionais de marketing precisam tornar seu produto amplamente disponível nas lojas.

A tomada de decisão limitada, para Churchill Jr. e Peter (2005) necessita de um número considerável de tempo gasto na realização da pesquisa na hora da compra, além disso, traz em alguns momentos limitações que são impostas ao consumidor, como a limitação financeira que ocorre quando os recursos financeiros disponíveis do consumidor não são compatíveis com as marcas que estão disponíveis para a compra. A limitação geográfica, que ocorre quando a região do consumidor é desfavorecida por não haver as marcas desejadas por ele, e a limitação de informação, que ocorre quando há pouca ou nenhuma informação sobre a marca do produto que o consumidor está pesquisando.

Nesse tipo de decisão o envolvimento do consumidor com a compra é considerado como moderado. Durante sua pesquisa o consumidor frequenta várias lojas e observa várias marcas, utilizando informações sobre o produto desejado através de fontes como amigos e propagandas. No decorrer deste processo os consumidores estão dispostos a gastar um pouco mais do seu tempo afim de adquirirem valor, porém de olho em suas limitações e esforço (Churchill \& Peter, 2005).

No entendimento de Churchill Jr. e Peter (2005) ocorre a tomada de decisões extensivas para a compra de produtos mais complexos, caros ou que representa um valor muito significativo para o consumidor. Para esse tipo de decisão o consumidor avalia diversas alternativas de marcas, produtos ou serviços, e as avaliam cada uma de acordo com suas características. Durante esse processo, o consumidor costuma consultar diversas fontes para obter informação do objeto, sites de buscas, especialistas, vendedores, propaganda, amigos e informativos. Para que isso ocorra, é necessária uma grande quantidade de tempo e esforço por parte do consumidor.

Ainda sob o entendimento de Churchill Jr. e Peter (2005), os profissionais de marketing afim de atender as exigências desse tipo de consumidor, devem estar aptos a entregar valor na forma de mensagens de marketing comparando alternativas entre os atributos oferecidos pelos produtos que o consumidor almeja. De outra maneira, afim de atender os consumidores que optam por uma tomada de decisões extensiva, porém se limitam nos esforços durante a pesquisa, podem estar sendo oferecido valor através de vendedores e atendentes bem informados sobre uma variação de marcas e produtos, podendo assim ajudar os clientes 
em sua busca.

\section{Procedimentos Metodológicos}

Sob as perspectivas de Gil (2008), a pesquisa de natureza aplicada ou prática, afim da aplicação imediata de resultados, traz consigo a necessidade de aproximação e conhecimento do seu entrevistado.

Portanto, referente à natureza da pesquisa, a mesma trata-se de uma pesquisa aplicada, visto que os dados abordados por ela geram conhecimentos a respeito do desenvolvimento e utilização do marketing pelos feirantes, além de indicar como os seus elementos estão associadas as práticas no dia a dia do ambiente comercial feirante, assim dirigindo-os para a solução de problemas específicos.

No que diz respeito ao modelo de abordagem do problema, o presente estudo se fez de modo predominantemente quantitativo. Quanto ao esclarecimento do modelo de abordagem utilizado neste estudo, Malhotra (2012), destaca que, a pesquisa quantitativa transforma os dados coleados em números e, posteriormente, busca aplicar uma análise estatística a eles.

Nessa etapa da pesquisa, afim de obter os dados para dar continuidade a pesquisa, fez-se necessário a aplicação de um questionário estruturado (Apêndice A) aos consumidores feirantes que frequentam a Feira Bela Vista, instalada na Praça Rodrigues Liberato de Santana, na cidade de Dianópolis- TO.

Portanto, ao obter a média de visitantes observadas em Outubro a Dezembro de 2020 (com pequenas variações entre os meses, inclusive no mês de a, por possuir 5 sextas-feiras) foi possível classificar a população-alvo como, sendo uma média de 650 clientes por mês que frequenta a Feira Bela Vista. Logo a pesquisa foi direcionada para este público, sendo que o estudo contou com uma amostra de 218 clientes respondentes.

A aplicação dos questionários se deu através de uma ferramenta do Google, chamada Google forms, sendo buscado, tão somente, as pessoas que frequentam e consomem produtos na feira, local do estudo, no período de Outubro a Dezembro de 2020. Em nenhum momento o pesquisador ajudou ou expressou-se no momento do preenchimento das questões, visando a sinceridade dos respondentes.

Para sintetizar e aproximar os dados quantitativos à uma forma simétrica, fez-se uso da média aritmética ponderada, sendo essa medida estatística empregada nas questões relacionadas ao Bloco $\mathrm{C}$ do questionário, e no Bloco D, no programa Microsoft Excel. Para tal, multiplicou-se cada valor do conjunto de dados pelo seu peso (que foi definido de acordo com a pontuação da escala Likert). Posteriormente, ao encontrar a soma desses valores foi feito uma divisão pelo número de respondentes. Segue abaixo a fórmula utilizada nessa etapa:

$$
\frac{m_{p}=p_{1} \cdot x^{1}+p_{2} \cdot x^{2}}{n}
$$

\subsection{Distribuição de frequência}

Essa distribuição matemática, segundo Malhotra (2012), tem a finalidade de sistematizar a frequência das respostas relacionadas a diversos valores de uma variável e, posteriormente, torna-se possível sua apresentação em forma de porcentagem.

Ainda sob as perspectivas do autor, essa técnica é considerada como sendo a mais simples utilizada para as demonstrações de resultados, pois se refere a um agrupamento de dados em classes, onde contabiliza-se o número de ocorrências em cada classe. Com a apuração desse número a classe é intitulada por frequência absoluta.

Com o objetivo de apresentar os dados de uma maneira mais concisa e que ao mesmo tempo permitisse a extração de informações sobre as características, comportamento e opinião dos consumidores sobre os elementos do mix de marketing, a distribuição de frequência, neste caso, foi realizada na plataforma do Google forms, propiciando, por conseguinte, a demonstração 
dos resultados através de gráficos e tabelas, sendo os resultados da pesquisa retratados por meio de porcentagem.

\subsection{Desvio padrão}

Segundo Gouveia (2018) o desvio padrão refere-se a uma medida estatística que revela o nível de dispersão de um agrupamento de dados. Isto é, essa medida busca expressar a uniformidade dá um determinado conjunto de dados. Quanto menor a for a distância do número zero, mais harmônicos são os dados.

Ainda de acordo com a autora, o desvio padrão (DP) é delineado através da raiz quadrada da variância (Va):

$$
\mathrm{Dp}=\sqrt{v a}
$$

A apuração do desvio-padrão foi utilizada nos resultados das questões do Bloco $\mathrm{C}$ e no Bloco $\mathrm{D}$ do questionário, por intermédio do programa Microsoft Excel, com o objetivo de reconhecer o comportamento dos resultados da distribuição em torno da média.

\section{Resultado e Discussões}

\subsection{Histórico da Feira Bela Vista}

A Organização dos Feirantes Bela Vista (OFBV) teve seu início em 2016 com o intuito de trazer um pouco da cultura e agricultura familiar para o cidadão Dianopolino. Os feirantes que fazem parte desse grupo de trabalhadores são, em sua maioria, da zona rural, com idade superior a trinta e cinco anos. O local da aplicação do estudo, antiga rodoviária, é apenas mais um dos locais no qual os trabalhadores que fazem parte desse grupo se instalam. Nesse local onde foi aplicado o estudo, considerado como um novo ponto de instalação, as atividades da OFBV tiveram início a cerca de dois anos.

A feira, hoje, conta com pouco mais de sessenta e dois feirantes, sendo que desses, alguns não são tão ativos quanto outros. Os primeiros feirantes sobrechegaram após surgir a ideia de ampliar o seu ambiente feirante e atingir outros setores. Isto é, levar a sua cultura, credibilidade e responsabilidade da sua agricultura familiar para os lares de seus consumidores. É importante ressaltar que a OFBV ainda não possui uma associação formal, hora por falta de apoio de representantes políticos, hora por falta de uma definição de um líder da sua organização feirantes.

Alguns dos principais produtos oferecidos pelos feirantes da OFBV são hortifruti (produtos produzidos em hortas, como frutas, legumes, hortaliças etc.), de açougue (carne bovina, suína, de aves, e peixes), alimentos perecíveis (lanches e pratos: salgados, caldos, refeições, etc.), de padaria (bolos, pães, etc.), lácteos (leite bovino, queijos e seus derivados), de bebidas (etílicas, refrigerantes e sucos) e entretenimento infantil (pula-pula).

\subsection{Perfil dos consumidores da Feira Livre}

A primeira variável do questionário é relacionada ao perfil do consumidor, e visou conhecer o gênero dos clientes que responderam o questionário, identificando-se como consumidores da Feira estudada. Verificou-se que a frequência do gênero feminino supera a do gênero masculino, sendo $58,3 \%$ o público feminino e $41,7 \%$ o público masculino. Ou seja, para cada dez pessoas, quase seis pessoas são mulheres e apenas quatro são homens.

A segunda variável que ilustra o perfil do consumidor que respondeu aos questionários no período supracitado, foi referente ao estado civil dos consumidores. Destes, mais da metade são solteiros 53,2\%, 43,1\% casados, 0,5\% divorciados, nenhum viúvo e 3,2\% outro, notamos que 53,9\% das pessoas não possuem um relacionamento formalizado.

A terceira variável relata as informações dadas à pergunta do questionário referente à idade do respondente. Analisando de modo geral, quando comparado com as demais percentagens, nota-se que os consumidores feirantes tratam-se de um grupo composto, em sua maioria, por um público jovem, pois, dentre os 218 (duzentos e dezoito) questionários avaliados, a maioria, 
$44 \%$, está na faixa etária entre 14 a 25 anos. Em seguida, com 25,2\% estão os consumidores com idade entre 26 a 40 anos; $23,9 \%$ possuem entre 41 e 50 anos; e apenas $6,9 \%$ têm mais que 50 anos de idade.

Dessa maneira, pode-se concluir que os respondentes dessa pesquisa pertencem a um grupo de consumidores jovens e adultos, uma vez que, ao juntar as três primeiras faixas etárias consideradas, entre 14 a 40 anos, soma-se 69,2\% dos questionários respondidos, sendo a maioria solteiros e do sexo feminino.

\section{Fatores que influenciam o comportamento do consumidor feirante}

O marketing surge a partir dos desdobramentos e junções de diversos estudos científicos que buscam tanto revelar o comportamento das pessoas quanto descobrir as suas necessidades e desejos para, a partir disso, satisfaze-los (Shimoyama \& Zela, 2002).

O estudo sobre o comportamento do consumidor, para Schiffman e Kanuk (2000), engloba a identificação das necessidades de aquisição daquele produto ou serviço por parte do consumidor. Ou seja, o estudo sobre o que compram, o porquê, quando, onde, e também a sua frequência.

Figura 2 - Principais motivos para frequentar a feira.

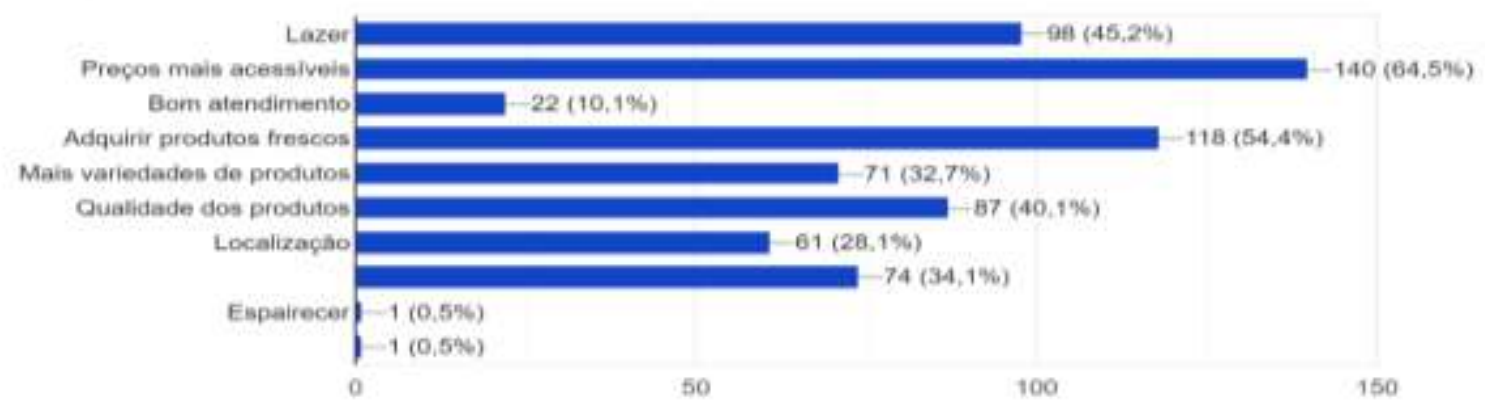

Fonte: Autores, com base nos dados coletados.

Nessa primeira variável do comportamento do consumidor feirante buscou-se, através de uma questão de múltipla escolha, onde foi permitido marcar mais de uma opção, identificar as principais influencias que servem como motivação para explicar a frequência de visitas do consumidor feirante e, respectivamente, a suas compras na Feira Bela Vista.

O estudo revela que a maioria dos consumidores feirantes são motivados a frequentar a Feira Bela Vista devido esse ambiente comercial feirante proporcionar-lhes preços mais acessíveis $(64,5 \%)$.

Tendo em vista a constante evolução do marketing citada por Kotler (2000), onde tal ferramenta deixou de ser vista apenas como uma "arte de vender", passando a ser uma ciência utilizada para conquistar e manter clientes, melhorando a relação entre ambos (vendedor e consumidor), percebe-se, através desse estudo que, ao comparar os fatores influenciadores da Figura 2, o Bom Atendimento, um dos principais fatores responsáveis pela durabilidade da relação com o cliente e consequentemente sua fidelização é, de acordo com os consumidores, um dos menores motivos que os levam à Feira Bela Vista. Sendo apenas $10,1 \%$ dos consumidores influenciados pelo bom atendimento.

Pode ser observado, também, na Figura 2, que um dos principais fatores que influenciam os consumidores a frequentarem a Feira são a facilidade de encontrar produtos frescos $(54,4 \%)$, o lazer $(45,2 \%)$, e a qualidade dos produtos $(40,1 \%)$.

E, o que menos os motivam são a localização $(28,1 \%)$, a variedade dos produtos $(32,7 \%)$ e o consumo imediato de algum produto $(34,1 \%)$.

A relação a longo prazo da empresa e cliente está ligada a satisfação ou a insatisfação do cliente. Com o cliente satisfeito 
as chances de uma nova compra e fidelidade ao produto da empresa são maiores. Já em contrapartida, quando há a insatisfação, a propaganda negativa de boca a boca pode prejudicar a imagem da empresa e respectivamente o fluxo de cliente e de fidelizações (Kotler, 2000).

O baixo valor motivacional dado a alguns itens da Figura 2 podem ser explicados pelo conceito do marketing informal, que tratar-se, em suma, de atividades inovadoras e sensitivas, composta por conhecimento empírico, sendo suas práticas orientadas ou executadas de modo não estruturados tendo como finalidade apenas a transação comercial (Souza, 2016).

Quadro 1 - Frequência de Visitas.

\begin{tabular}{|c|c|}
\hline Categorias & Frequência \\
\hline Uma vez no mês & $34,6 \%$ \\
\hline Até 2 vezes no mês & $19,8 \%$ \\
\hline Até 3 vezes no mês & $38,7 \%$ \\
\hline Todas as sextas-feiras & $6,9 \%$ \\
\hline Total & $\mathbf{1 0 0 \%}$ \\
\hline
\end{tabular}

Fonte: Autores, com base nos dados coletados.

Ao avaliar os principais motivos pelo qual os consumidores frequentam a Feira Bela Vista, fez-se necessário, ademais, analisar a frequência com que as pessoas a frequentam, independentemente do motivo, podendo, então, essa visita ser motivada por qualquer fator supracitado na Figura 2.

Avaliando os dados acima (Quadro 1) observa-se que o número de pessoas que frequentam a Feira Bela Vista, todas as sextas-feiras, é expressamente baixo, sendo este apenas 6,9\%. Esse baixo número de fidelização pode estar intimamente ligado a baixíssima motivação externa fornecida pelos feirantes, como pôde ser identificado na Figura 2, onde o Bom Atendimento representava apenas $10,1 \%$ como sendo um dos fatores motivacionais responsáveis por dirigir os consumidores novamente ao ambiente feirante.

A maioria dos consumidores visitam a Feira estudada apenas uma ou duas vezes no mês $(54,4 \%)$, e outros consumidores costumam frequentá-la até três vezes durante o mês $(38,7 \%)$.

Quadro 2 - Formas de Pagamentos.

\begin{tabular}{|c|c|}
\hline Categorias & Frequência \\
\hline Dinheiro & $98,2 \%$ \\
\hline Cartão de débito & $1,8 \%$ \\
\hline Cartão de crédito & $0 \%$ \\
\hline Total & \\
\hline
\end{tabular}

Fonte: Autores, com base nos dados coletados.

O único elemento do Mix de Marketing que gera receita diretamente para a empresa é o preço, já os outros "Ps" são responsáveis por gerarem custos (Kotler \& Keller, 2006).

Antes da realização da compra, o consumidor ainda pode passar por cinco subdivisões de decisões, podendo sua decisão ser ocasionada pela marca, fornecedor, quantidade, ocasião e forma de pagamento (Kotler, 2000).

De acordo com essa variável e as informações capitadas referentes a uma variante de um elemento dos 4ps - a política 
dos meios de pagamentos -, pode ser notado, de um modo geral, que a Feira Bela Vista se limita, praticamente, a uma única forma de pagamento, o dinheiro $(98,2 \%)$, já que a utilização do cartão de débito $(1,8 \%)$ e de crédito $(0 \%)$ são de pouco, ou nenhum uso dentro do ambiente comercial feirante

Figura 3 - Formas de pagamentos que gostariam de utilizar.



Fonte: Autores, com base nos dados coletados.

Afim de satisfazer as necessidades e desejos dos consumidores antes, durante e depois, é importante que as empresas compreendam a forma que os seus clientes-alvos compram (Nickels; Wood, 1999).

Apercebe-se, com essa variável, a insatisfação dos consumidores com as limitações dos meios de pagamentos presentes na Feira estudada. Contudo, o dinheiro continua sendo a principal forma de pagamento, tanto utilizada, como foi expresso anteriormente (Quadro 2), quanto desejada (Figura 3), sendo escolhido de forma singular por mais de setenta e cinco pessoas, ou seja $38,1 \%$.

Todavia, é necessário, pois, analisar, que por outro lado 61,9\% pensam de forma contrária, optando por mesclarem suas formas de pagamentos, como é o caso dos consumidores que desejam efetuar as suas compras com os cartões de crédito e débito $(21,1 \%)$, somente com o cartão de débito $(15,6 \%)$, com o dinheiro e cartão de débito (17\%), com as três opções $(3,7 \%)$, somente com o cartão de crédito $(4,1 \%)$, e também com o cartão de crédito e com o dinheiro $(0,5 \%)$.

Figura 4 - Pesquisa e comparações de preços.

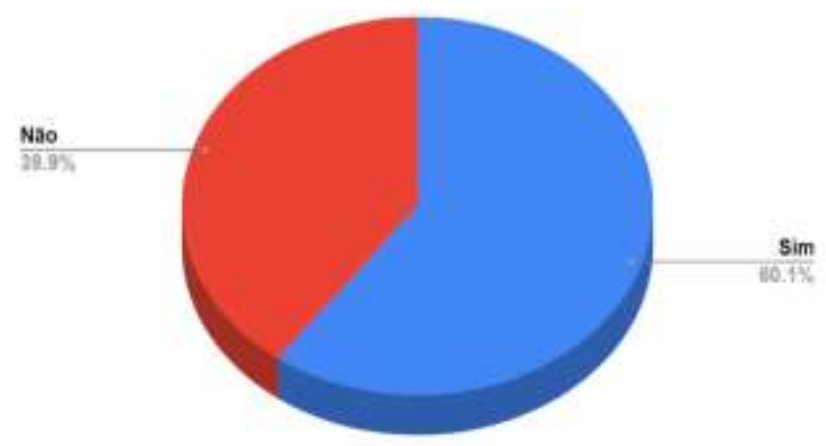

Fonte: Autores, com base nos dados coletados. 
Um dos grandes responsáveis pelas alterações e definições do preço é a concorrência e os próprios consumidores, ambos são uma variável muito importante no desenvolvimento das estratégias de preços das empresas (Las Casas, 2006).

Através dessa variável identificou-se que 39,9\% não realizam pesquisa ou comparações de preços na Feira, e 60,1\% dos consumidores sim, costumam realizar pesquisas e comparações das precificações dos produtos da Feira em relação a outros ambientes comerciais. A partir da análise dessa variável, depreende-se que esses consumidores supracitados acabam engajando, de certa forma, o aumento da competitividade e de preços mais acessíveis, sendo esse último, informado na Figura 2, o principal fator motivacional para ir à Feira estudada.

Em geral, de acordo com Churchill Jr. e Peter (2005), a importância que o consumidor dá para uma determinada compra é o que definirá a sua decisão final de compra, ou seja, os consumidores não seguem rigorosamente as etapas do processo de decisão de compra.

\section{Considerações Finais}

Com base no objetivo geral desse trabalho buscou-se analisar a influência do Mix de Marketing na tomada de decisão do consumidor em uma feira livre, para tanto, foi realizado uma pesquisa por meio de um questionário, sendo esse instrumento de coleta de dados aplicado aos consumidores feirantes que frequentam a Feira Bela Vista, instalada durante as sextas-feiras na Praça Rodrigues Liberato de Santana (antiga rodoviária), em Dianópolis, TO.

Com a realização dessa pesquisa tornou-se possível levantar o perfil dos consumidores que frequentam a Feira Bela Vista, sendo esses, em sua maioria, um público do sexo feminino (58,3\%). Um público predominantemente solteiro(a) (53,2\%), compostos por jovens e adultos, sendo esses 69,2\% abaixo dos 40 anos de idade.

Em relação aos fatores que influenciam à tomada de decisão do consumidor, pode-se afirmar, com base nos resultados da pesquisa, que os consumidores que frequentam a Feira estudada são influenciados principalmente por questões como a qualidade dos produtos $(52,6 \%)$, responsável por influenciar os consumidores através da sua qualidade e adaptação às necessidades específicas que o consumidor possui; a acessibilidade e visibilidade dos preços (62\%), sendo considerado um dos elementos mais influentes nas decisões rotineira, pois o consumidor tende a dar preferência a um produto com preço mais acessível; a segurança e estrutura da feira (72\%), sua influência na tomada de decisão interfere no sentido de tornar um produto de fácil acesso e disponível ao consumidor, enquanto que a segurança compete diretamente a uma necessidade básica; e a divulgação e o oferecimento das promoções $(77,8 \%)$, capaz de influenciar os consumidores em todos os estágios do processo de compra.

Portanto, através desses dados verificou-se que fatores pessoais, culturais e de estímulos de marketing influenciam diretamente à tomada de decisão do consumidor, pois através dos fatores supracitados o consumidor adota tanto a sua decisão final de compra, quanto as suas decisões com relação ao pós-compra, podendo este se fidelizar ao ambiente ou não indica-lo a terceiro.

É importante ressaltar, também, que variantes como a qualidade dos produtos e a acessibilidade dos preços, variantes extremamente importantes dentro dos 4 ps, foram avaliadas de formas positivas pelos consumidores, porém, tal satisfação tornase não compensatória, visto a tamanha insatisfação dos consumidores com a visibilidade dos preços, formas de pagamentos, organização e estrutura da feira, fatores fundamentais na decisão de compra e pós-compra.

Em relação as limitações, em um primeiro momento, a aplicação do questionário dar-se-ia de maneira presencial, face a face com o pesquisado, porém, devido a identificação de uma sazonalidade de frequentadores da feira, durante as visitas feitas, optou-se por aplicar o questionário através da ferramenta do Google forms. Quanto as recomendações para estudos futuros, recomenda-se expandir o estudo a um campo maior de pesquisa, para que assim seja captadas mais opiniões e percepções acerca do tema proposto. 


\section{Referências}

Barcellos, R., \& Scelela, S. S. (2012). Marketing e Vendas. Instituto Federal de Educação, Ciência e Tecnologia. - Paraná - Educação a Distância.

Chiavenato, I., \& Sapiro, A. (2003). Planejamento Estratégico: fundamentos e aplicações. Elsevier,

Churchill, JR. G. A., \& Peter, J. P. (2000). Marketing: Criando valor para os clientes. Saraiva.

Churchill, G. A., \& Peter, J. P. (2005). Marketing: criando valor para os clientes. Saraiva.

Cobra, M. (1992). Administração de marketing. Atlas.

Czinkota, M. R., \& Dickson, P. R. (2001). Marketing: as melhores práticas. Bookman.

Jardim, J. C. S. (2005). Marketing de Serviços. 2005. Universidade Candido Mendes.

Gerhardt, T. E., \& Silveira, D. T. (2009). Métodos de pesquisa. UFRGS.

Gil, A. C. (2008). Métodos e Técnicas de Pesquisa Social. Atlas.

Kotler, P. (2000). Administração de marketing: a edição do novo milênio. Pearson Prentice Hall.

Kotler, P. (2005). Administração de marketing. Prentice Hall.

Kotler, P., \& Keller, K. L. (2006). Administração de Marketing. Prentice Hall.

Kotler, P. \& Armstrong, G. (2007). Princípios de Marketing. Pearson Prentice Hall.

Kotler, P., \& Keller, K. L. (2012). Administração de Marketing. Pearson Education do Brasil.

Las casas, A. L. (2006). Marketing: conceitos, exercícios, casos. Atlas.

Malhotra, N. K. (2012). Pesquisa de marketing: uma orientação aplicada. Bookman.

Marconi, M. D. A., \& Lakatos, E. M. (2003). Fundamentos da Metodologia Científica. Atlas.

Marconi, M. D. A. \& Lakatos, E. M. (2010). Fundamentos da metodologia científica. Atlas.

Nassaralla, J. A. (2006). Feiras setoriais em APL's como fenômeno de marketing: o caso FEVEST. Dissertação (Mestrado em Administração e Desenvolvimento Empresarial) - Universidade Estácio de Sá, Presidente Vargas.

Nickels, W. G., \& Wood, M. B. (1999). Marketing: relacionamentos, qualidade, valor. LTC.

Paes, P. C.\& Pereira, S. A. W. (2008). A importância das ferramentas do marketing nas pequenas empresas. Garça.

Prodanov, C. C., \& Freitas, E. C. D.(2013). Metodologia do trabalho científico. Feevale.

Rodrigues, J. N. (2005). 50 Gurus Para o Século XXI. Centro.

Rocha, R. A. \& Platt, A. (2015). Administração de marketing. Departamento de Ciências da Administração/UFSC.

Santos, M. (2016). Sobre: Microempreendedor Individual. Site do Administradores https://administradores.com.br/artigos/microempreendedor-individual

Santos, V. \& Candeloro, R. J. (2006). Trabalhos Acadêmicos: uma orientação para a pesquisa e normas técnicas. Age.

Sebrae. (2018). Pequenos negócios em números. http://www.sebrae.com.br/sites/PortalSebrae/ufs/sp/sebraeaz/pequenos-negocios-em- numeros,12e8794363447 510Vgn VCM1000004c00210aRCRD

Silva, S. G. H. (2014). Marketing informal: um modelo de comercialização pautado em jeitinho brasileiro, informalidade e Empreendedorismo. Revista Brasileira de Marketing, 13(3), 677.

Schiffman, L. G., \& Kanuk, L. L. (2000). Comportamento do consumidor. LTC.

Shimoyama, C., \& Zela, D. R. (2002). Administração de marketing. Unifae/Gazeta do Povo.

Souza, C. (2016). Sobre: Marketing Digital a Evolução do Marketing. https://administradores.com.br/artigos/marketing-digital-a-evolucao-do-marketing

Steffen, R. A. A. (2009). Influência do mix de marketing e dos fatores comportamentais nas decisões do consumidor: O Caso SAYURI Produtos Orientais. Universidade Federal de Santa Catarina, Florianópolis.

Zikmund, W. G. (2006). Princípios da pesquisa de marketing. Pioneira Thomson Learning. 